anteroposterior view and submentovertical view. Postmortem examination and procedure to be designed and developed for this particular region and for this purpose.

One may hope that the individual and corporate effort which may be expended testing and perhaps developing my proposition will yield knowledge that will lead to preventive measures eventually if not directly. Coordination of efforts with workers in the field of the sudden infant death syndrome will be sought.-I am, etc.,

Stoneygate,

O. ENGLANDER

1 Englander, O., British fournal of Radiology, 1942, 15, 341.
Coutts, M. B., Archives of Surgery, 1934, 29, 297.

\section{Anaesthesia for Cardioversion}

SIR,-We read with interest the paper by Professor K. Somers and others (2 October, p. 13) on intravenous diazepam for cardioversion and the subsequent letter by Drs. S. M. Lyons and R. S. J. Clarke (23 October, p. 228). Our experience has been similar to that of Professor Somers and others. We have studied 10 patients undergoing diagnostic cardiac catherization for evaluation of a variety of acquired cardiac lesions. The patients were unpremedicated and fasting prior to the procedure. Intravenous diazepam $(0.1 \mathrm{mg} / \mathrm{kg})$ was administered via a catheter in the pulmonary artery and recordings of arterial pressure made via an indwelling aortic catheter 10 and 20 minutes later. In addition, cardiac output, and right ventricular $\mathrm{dP} / \mathrm{dT}$ were also measured. None of these parameters showed any significant change from control values during the period of observation.

We feel that the discrepancy between the observations of Professor Somers et al. and those of Drs. Lyons and Clarke is probably due to the premedication administered by the latter.-We are, etc.,

HAMID IKRAM

A. P. RUBIN

Charing Cross Hospital,

Charing Cross

\section{Handicapped Children in Preschool} Playgroups

SIR,-It was with great interest that we read the article on "Handicapped Children in Preschool Playgroups" by Dr. Elizabeth Grantham (6 November, p. 346). As part of the paediatric team in this hospital we have facilities for detailed developmenal assessment and also a remedial playgroup. A regimen is specially designed for each child depending on his handicap. This is carried out under the supervision of the physiotherapists and occupational therapists in the remedial playgroup.

All that Dr. Grantham says has been borne out by our experience and we feel very strongly that to obtain the maximum benefit from admission to outside playgroups this specialized tuition is essential. In this way we have overcome many of the problems mentioned in her article. When parent and child have been taught the exercises and special stimulation needed for the specific handicap we then manage to place many of our children in outside playgroups and we are able to pass on detailed information on the specific needs of each child. This ensures correct stimulation and understanding of the child by the outside playgroup, who will know where to seek further help if additional problems arise.-I am, etc.,

Poole General Hospital,

A. S. RAIKES Poole, Dorset

\section{Breast-milk Jaundice and Ora Contraceptives}

SIR,-The article by Dr. Y. K. Wong and Dr. B. S. B. Wood on "Breast-milk Jaundice and Oral Contraceptives" (13 November, p 403) is thought-provoking and further study is clearly required. However, is the title not misleading? A study was made of only breast-fed infants. They were classified on a basis of whether the mother had been on the "pill" or not. If the authors had also studied infants who were not breast-fed we might have some idea as to whether breast feeding was a contributory factor, perhaps an essential requirement. The design of the study leaves us ignorant on this point. It is hoped that the authors will extend their work to answer this important question.am, etc.,

School of Medicine,

G. H. LATHE

University of Ieeds

\section{Thiopropazate Hydrochloride in Persistent} Dyskinesia

SIR,-We would like to add the following addenda to our paper (2 October, p. 22) in which we reported that thiopropazate (Dartalan) was significantly more effective than a placebo in relieving dyskinesia in patients with functional psychosis and per sistent dyskinesia associated with prolonged phenothiazine therapy:

ADDENDUM I: Thiopropazate was also found to be more effective than a placebo in relieving dyskinesia in 15 patients with organic psychosis. The differences were statistically significant in all three rating scales for dyskinesia. The trial was doubleblind with cross-over as already described. These patients were, in fact, inadvertently included in the original trial.

\section{Diagnostic Categories}

Presenile and senile dementias General paralysis of insane

Psychosis associated with epilepsy

Cerebral arteriosclerosis Total $\overline{15}$

AdDENDUM II: Perphenazine (Trilafon) a piperazine derivative of phenothiazine, in a dose of $8 \mathrm{mg}$ three times daily was found to be effective in relieving dyskinesia in 14 patients with functional psychosis and prolonged phenothiazine intake. Pretrial and post-trial scores at the end of three week were significantly different in all three scales. The trial, however, was not blind.

Perphenazine was selected for evaluation because this is probably the active substance in the organism when thiopropazate is administered (the thiopropazate being broken up into perphenazine and acetic acid).-We are, etc.,

K. SINGER

Mental Health Service, M. N. CHENG

Hong Kong Psychiatric Centre, Hong Kong

\section{Seat-belt Fasteners}

SIR,-In reply to Dr. C. W. A. Emery (13 November, p. 430) may I point out that for some years past seat belts have been compulsory front-seat fittings in all cars registered since 1 January 1965?

All seat belts must comply with laid-down British Standards, and new standards defined last month will make them even more comfortable to wear and, to an extent, safer. As each belt manufacturer uses his own design there is at present a wide variety of buckles, but the problem posed for an unfamiliar would-be rescuer in an emergency is more apparent than real, as most are clearly labelled with their modus operandi, "Lift," "Press," etc.

Under legislation put before Parliament in July last cars registered after 1 April 1973 will have to be fitted with "one-handedaction" seat belts which must be able to be put on and fastened in one singlehanded movement and similarly unclipped and stowed again after use. When stowed they must leave the floor uncluttered. This requirement will virtually eliminate the short centre-mounted strap which tends to get lost under the seat. Britax pioneered the singlehanded British belt with their "TwinLock," in which the buckle tongue slots into a centrally fixed box, to be released by pressure upon a clearly labelled lever. Healthy competition in detail design is good for developmental progress.

Years ago I had the unpleasant experience of finding myself hanging by my Britax lapand-diagonal belt in an overturned car. I can reassure Dr. Emery that I had no trouble at all in instantly unclipping the buckle to emerge without a scratch. Unbelted, I feel I would have been quite seriously injured in that accident. The essential thing is for us to get into the habit of always using the everbetter belts available, lest under pressure we are forced to buy passive restraint systems which may give poorer protection but will inevitably cost a lot more.-I am, etc.,

KeIth E. Jolles

Birmingham 8

\section{Casualties}

SIR,-We take the point raised by Mr. W. H. Rutherford (13 November, p. 427) about our use of the adjective "casual" in our paper (23 October, p. 214). While nobody who read our report could be in any doubt about our definition of the word, we accept that "nonreferred" is a preferable alternative which is less likely to be misinterpreted.

We are less happy about the implication in Mr. Rutherford's letter that we advocated minor accident departments in health centres which would be run entirely by nurses. We did point out the need for appropriate safeguards, and for the availability at all times of medical advice and skill. Given these conditions, we think that experienced nurses are well able to undertake a certain amount of primary and followup care, as indeed they are doing in clinics, health centres, group practices, and, probably, accident departments up and down the country. We believe that accident department staffs, members of the primary care team, and patients will all benefit if more non-referred sufferers from minor accidents 